Open access publication - https://doi.org/10.5281/zenodo.3555047

Final manuscript accepted for publication in Applied Radiation and Isotopes 155 (2020) 108907, pp 1-9

\title{
AN INNOVATIVE QUICK METHOD FOR TRACABLE MEASUREMENT OF RADON 222 IN DRINKING WATER
}

Franz Josef Maringer ${ }^{1 *}$, Hannah Wiedner ${ }^{1}$, Francesco Cardellini ${ }^{2}$

${ }^{1} \mathrm{BEV}$ - Bundesamt für Eich und Vermessungswesen, Arltgasse 35, 1160 Wien, AUSTRIA

${ }^{2}$ ENEA - National Institute of Ionizing Radiation, Centro Ricerche Casaccia, ITALY

9

Keywords: Radon 222 activity concentration; traceable calibration; drinking water; radon emanation; ionisation chamber; uncertainty budget; characteristic limits; ISO 11929:2010; ON S 5250-1:2001

\section{Abstract}

In this work, a quick and simple low-level radionuclide metrology technique for the traceable measurement of Rn-222 activity concentration in drinking water using a $0.56 \mathrm{l}$ ionisation chamber operating in spectrometric pulse mode has been developed, tested, verified and applied to 16 water samples successfully. The impact of essential influencing factors on the result has been investigated, discussed and considered in the uncertainty budget of the measurement method. Finally, the new method has been assessed regarding the applicability on the EU Council Directive 2013/51.

Publication in Applied Radiation and Isotopes:

* Corresponding author.

E-mail address: franz-josef.maringer@bev.gv.at (F.J. Maringer).

Received 6 May 2019; Received in revised form 23 September 2019; Accepted 26 September 2019 Available online 30 September 2019

0969-8043/C 2019 Elsevier Ltd. All rights reserved. 


\section{Introduction}

Radon (in this context radon refers to the isotope Rn-222), a naturally occurring radioactive noble gas, is a daughter of primordial U-238 and as such is present in many soils, rocks and building materials from where it emanates into the atmosphere. It is generated by alpha decay of Ra-226 that is in turn generated through a series of decays in the uranium radium series. Rn-222 further decays via alpha decay with a half-life of 3.8232(8) days and an alpha energy of 5 589,48(39) keV (99,92(1) \%) into Po-218 (DDEP, 2019). Inhalation of radon gas causes by far the largest part of the average annual effective dose to humans due to natural influences and accumulation in poorly ventilated buildings or mines can lead to potentially harmful activity concentrations (UNSCEAR, 2010). Approximately $80 \%$ of the worldwide annual effective dose per caput ( $3 \mathrm{mSv} / \mathrm{a})$ is attributed to natural sources of radioactivity $(2.4 \mathrm{mSv} / \mathrm{a}$ per caput), with approx. $40 \%$ (1.6 mSv/a per caput) caused by the inhalation of radon gas alone (UNSCEAR, 2010). Under Articles 35 and 36 of the EURATOM Treaty EU Member States are obligated to continuously monitor and report radioactivity levels in air, water and soil (European Union, 2016) to ensure radiation protection of the public.

The greatest potential danger of radon in water is not the occurrence in drinking and household water, where concentrations are usually quite low due to aeration steps taken beforehand, but the additional amount of radon released to the atmosphere, causing high dose rates when accumulation happens. A study on 45 waterworks in Upper Austria showed a yearly dose received by the workers exceeding $6 \mathrm{mSv} / \mathrm{a}$ in three of the investigated sites, two of them even exceeding the limitation for radiation exposed workers of $20 \mathrm{mSv} / \mathrm{a}$ (Ditto, et al., 2007). Where for human-made radionuclides the point at which they enter the water supply is often controllable, this is not the case for naturally occurring radionuclides that may enter the water supply at any or several points (WHO, 2011). High concentrations of Rn222's mother U-238 can be found in phosphatic and granitic rocks, as well as calc-silicate rock (Harb et al., 2012).

While radon, uranium and radium are all soluble in water, activity concentrations of Rn-222 in water can often be orders of magnitude higher than for other radionuclides (e.g. Ra-226, U235) (Ibrahiem, 2003; Fonollosa et al., 2016). Due to it being a noble gas, radon is neither ionized in solution nor precipitates in solid phases and - due to the commonly low partial pressure of radon in air - readily degasses from water into air which leads to much lower activity concentrations of radon in surface waters compared to ground waters (Gundersen and Wanty, 1993). The amount of radon in water and indoor air depends on many factors, such as type of usage of water (drinking water, shower, etc.), ventilation of the house, water agitation, surface area, etc. and degassing into indoor air increases significantly with temperature (Health Canada, 2009; UNSCEAR, 2000).

Several international organisations (NRC, 1999; UNSCEAR, 2000; WHO, 2011) have reported that approx. $90 \%$ of the dose attributable to radon in drinking water comes from inhalation rather than ingestion and most of the cancer risk associated with radon in drinking water comes from exhalation of radon gas to the surrounding air from where it may be inhaled. The water-to-air transfer factor of radon is typically $10 \cdot 10^{-4}$ (UNSCEAR, 2000), therefore, a radon concentration of $1000 \mathrm{~Bq} / \mathrm{L}$ would lead to an increase of approx. 100 $\mathrm{Bq} / \mathrm{m}^{3}$ in the radon concentration of indoor air. For an activity of $100 \mathrm{~Bq} / \mathrm{L}$ in drinking water, Rühle (1997) and UNSCEAR (2000) calculate an annual dose for an adult of $0.17 \mathrm{mSv} / \mathrm{a}$ and 
$0.25 \mathrm{mSv} / \mathrm{a}$ due to inhalation and $0.05 \mathrm{mSv} / \mathrm{a}$ and $0.02 \mathrm{mSv} / \mathrm{a}$ due to ingestion, respectively, totaling an increase of $0.22 \mathrm{mSv}$ and $0.27 \mathrm{mSv} / \mathrm{a}$, respectively, to the annual dose. Where water is supplied as part of a commercial or public activity, such as drinking water through a waterworks, the European Commission (2001) recommends $100 \mathrm{~Bq} / \mathrm{L}$ as indication level, below which no remedial action is required while for higher values, measurements should be conducted as necessary. Above $1000 \mathrm{~Bq} / \mathrm{L}$ remedial action may be required for radiation protection. Due to the large geographical variability in the natural occurrence of radon Member States shall ensure that representative surveys are undertaken to determine the scale and nature of likely exposures to radon in water intended for human consumption originating from different types of ground water sources and wells in different geological areas, focusing on geology and hydrology of the area, radioactivity of rock or soil, and well type (European Union, 2013).

Accurate measurement of radon activity concentrations in water are therefore of high importance. Measurement of radon in water can usually be performed relatively simply and cost-effective. Sample preparation is usually simple, quick and can be performed without the use of dangerous or expensive chemicals (Jobággy, 2017). A large number of measurement devices is in existence, suitable for both in-situ and laboratory conditions.

In principle, three different approaches are commonly used to analyse radon activity concentrations in water: gamma-ray spectrometry, emanometry and liquid scintillation counting (WHO, 2011; Jobággy et al., 2017, 2019, Wiedner et al, 2018). In its guidelines for drinking water, the World Health Organisation (WHO, 2011) gives no recommendation which technique should be used to measure radon activity concentration in drinking water. The method of analysis used must, however, as a minimum, be capable of measuring radon activity concentrations with a limit of detection of $10 \mathrm{~Bq} / \mathrm{L}$ according to the European Council directive 2013/51/Euratom laying down requirements for the protection of the health of the general public with regard to radioactive substances in water intended for human consumption (European Union, 2013).

Gamma-ray spectrometry of water samples is usually performed using HPGe detectors.

Radon activity concentration is derived from the measurement of radon's progeny Bi-214 and $\mathrm{Pb}-214$ after equilibrium has been established, therefore, the use of radon-tight sample containers is of utmost importance. No special sample preparation or treatment is needed.

Liquid scintillation counting is the most sensitive and widely used method for the determination of radon activity concentrations in water (WHO, 2011). A sample of water can be directly added to the scintillation cocktail using a gas-tight syringe. After thoroughly mixing sample and cocktail the scintillation vial is stored in a dark place to reduce photo luminescence effects and can then be measured using either alpha + beta or alpha-only mode.

For emanometry measurements, radon gas dissolved in water, is extracted from the sample and transferred to a radon-free gas environment like an ionisation chamber or scintillation cell where activity concentration is measured by counting alpha particles. Radon can be transferred by an inert gas flow or air circulation or vacuum (Jobbagy, 2017). A commonly used method is to bubble the water with radon-free gas (WHO, 2011). Previous studies showed that at normal temperature, a gas volume of at least three times the volume of the water sample is sufficient to completely de-emanate the water and release virtually all the radon gas from the water sample (WHO, 2011; Friedmann, 1977). After equilibrium of radon and its progeny is established, the measurement can be started. 
In this work, a quick and simple low-level radionuclide metrology technique for the traceable measurement of Rn-222 activity concentration in drinking water using a $0.56 \mathrm{l}$ ionisiation chamber operating in spectrometric pulse mode has been developed, tested, verified and applied to 16 drinking water samples. The input quantities, main measurement parameters and their uncertainties have been defined to establish an effective model equation for the resulting activity concentration of Rn-222 (Bq. $\left.\mathrm{l}^{-1}\right)$ in drinking water and a realistic uncertainty budget, respectively. The impact of essential influencing factors on the result has been investigated, discussed and considered in the uncertainty budget of the new traceable measurement method.

Finally, the results of the new method applied for the simple measurement of Rn-222 activity concentration in drinking water samples shows total relative measurement uncertainties in the range of $5 \%$ to $50 \%$, depending mostly on the time span between sampling and measurement due to the decay of Rn-222 (half-life 3.8232 days). The traceable measurement method has been verified via emanation of a Ra-226 standard water solution (PTB radioactivity standard). In conclusion the developed method is applicable in the field of radiation protection of the public for the traceable measurement of Rn-222 activity concentrations in drinking water.

\section{Materials and method's development}

\subsection{Drinking water sample collection}

The drinking water samples must be collected carefully avoiding degassing the solved Rn-222 from the water sample into the air. For this purpose, a small hose is connected to the tap water or spring water mounting. The hose is holding completely into the $1000 \mathrm{ml}$ gastight PET laboratory bottle (made of high-density polyethylene) when filling slowly the PET bottle with water. The water should overflow the bottle for some seconds before decanting quickly and carefully some $\mathrm{cm}^{3}$ of the water sample. This is for having some $\mathrm{cm}^{3}$ air space in the bottle in case of changing water density and pressure in the closed bottle due to temperature alternation. The filled bottles are transported to the laboratory at moderate temperatures between $15{ }^{\circ} \mathrm{C}$ and $25^{\circ} \mathrm{C}$. Before measurement, the water sample bottles have been stored at room temperature of about $22^{\circ} \mathrm{C}$ to $26^{\circ} \mathrm{C}$. The volume of the water samples have been determined by traceable mass measurement with a traceable calibrated laboratory balance and calculated based on a water temperature of about $12^{\circ} \mathrm{C}$ at usual water sampling conditions applying a water density of $0.9995 \mathrm{~kg} \cdot \mathrm{l}^{-1}$.

\subsection{Instruments assembly and measurement method}

The innovation of the herby introduced measurement method is the emanation into a relatively big calibration container barrel with a net air volume of $204.2(0.3)$ litres. This is a methodically advantage compared to the emanation methods filling the emanated radon directly into a small ionisation chamber with a volume of about $0.3 \mathrm{l}-1.0 \mathrm{l}$. The directly filling methods have the risk of uncalculable uncertainties because of unexpected loss of (high) radon activities, untight connections, and counting saturation effects because of too high radon (and progeny) activity concentrations in the ionisation chamber. In the hereby 
introduced method, the radon is completely emanated from the water bottle inside the barrel into the $204.2 \mathrm{l}$ air in the absolute air tight calibration container barrel, homogenised and measured with the traceable calibrated Austrian national standard for radon 222 activity concentration in air. This means generally, uncertainties which are specifically connected with the measurement air volume are reduced by a factor of about 1 / 200 compared with a directly filled ionisation chamber volume of about $1 \mathrm{l}$. The ionisation chamber has been positioned in the middle of the calibration container to ensure a highly representative measured Rn-222 activity concentration and reduce potential wall effects.

Before starting the emanation and measurement of the Rn-222 activity concentration of a water sample in the calibration container, the blank background rate $r_{0}\left(\mathrm{~s}^{-1}\right)$ of the used traceable calibrated ionisation chamber (Genitron Alpha Guard PQ $2000 \mathrm{Rn} / \mathrm{Tn}, \mathrm{S} / \mathrm{N}$ 1338) is determined. For this purpose, the calibration container is flushed with outdoor air at low Rn222 activity concentration $<5 \mathrm{~Bq} \cdot \mathrm{m}^{3}$. The blank background count rate is determined in a measurement period of $3600 \mathrm{~s} \mathrm{(1} \mathrm{h)} \mathrm{in} \mathrm{six} 10$ min subperiods. The ionisation chamber with an active measurement volume of $0.56 \mathrm{l}$ is used in diffusion mode and operated in alpha particle count mode.

After determination of the blank background count rate, the water samples are put into the calibration container barrel (Genitron Typ EV, S/N 03211, D 56 cm, H 86 cm, 210,1 l gross empty nominal volume) and carefully opened. A small degassing hose - connected on an air pump (Genitron Alpha Pump) - is then put into the water of the sample bottle (Figure 1). Then the calibration container is closed gastight and the air pump is switched on with a flow rate of $1 \mathrm{l} \cdot \mathrm{min}^{-1}$. The air circulates and is degassing the $\mathrm{Rn}-222$ from the water sample (Figure 2) into the barrel air volume. After about 20 min air circulation, Rn-222 is almost completely (>98\%) emanated out from the water sample and distributed homogeneously by a fan into the air volume of the calibration container.

20 min (1800 s) after start of the Rn-222 emanation from the water sample into the air of the closed calibration container, the diffusion of Rn-222 into the ionisation chamber is finished. Then the $3600 \mathrm{~s} \mathrm{(1} \mathrm{h)} \mathrm{measurement} \mathrm{period} \mathrm{starts.} \mathrm{After} \mathrm{finishing} \mathrm{the} \mathrm{data} \mathrm{processing,} \mathrm{the}$ calibration container is opened and flushed again with low Rn-222 fresh outdoor air establishing the blank background situation in the calibration container for the next sample measurement.

\subsection{Calculations}

The measurement calculations are based on the complete radon emanation out from the water sample bottle into the air of the calibration container barrel and measurement of the homogenised radon activity concentration of the barrel air by the traceable radon ionisation chamber. In this method it is necessary for keeping the traceability of the method completely to determine the net air volume (l) of the calibration container barrel traceable too.

The Rn-222 activity concentration in air $c_{\mathrm{A}}\left(\mathrm{Bq} \mathrm{m}^{-3}\right)$ in the calibration container barrel measured with the traceable ionisation chamber is 


$$
c_{\mathrm{A}}=w\left(r_{\mathrm{g}}-r_{0}\right)=w \cdot r_{\mathrm{n}}
$$

with

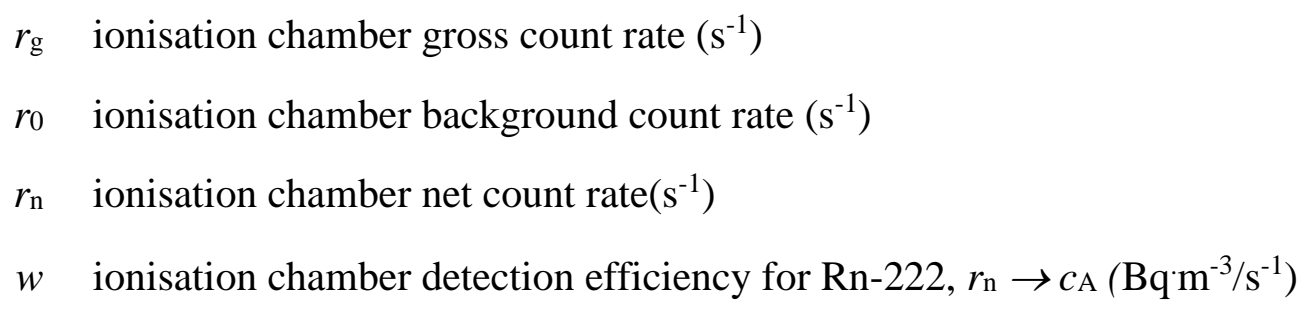

The standard uncertainty of the Rn-222 activity concentration in air $u\left(c_{A}\right)\left(B q m^{-3}\right)$ measured in the calibration container is

$$
u^{2}\left(c_{\mathrm{A}}\right)=r_{\mathrm{n}}^{2} \cdot u^{2}(w)+w^{2} \cdot u^{2}\left(r_{\mathrm{n}}\right)=c_{\mathrm{A}}^{2} \cdot\left(\frac{u(w)}{w}\right)^{2}+w^{2}\left(\frac{r_{\mathrm{g}}}{t_{\mathrm{g}}}-\frac{r_{0}}{t_{0}}\right)
$$

with

$$
\begin{aligned}
t_{\mathrm{g}} & \text { measurement period of the ionisation chamber gross count rate(s) } \\
t_{0} & \text { measurement period of the ionisation chamber background count rate(s) } \\
u(w) & \text { standard uncertainty of the ionisation chamber efficiency }\left(\mathrm{Bq} \cdot \mathrm{m}^{-3} / \mathrm{s}^{-1}\right)
\end{aligned}
$$

The detection efficiency $w$ for Rn-222 of the used ionisation chamber with an active volume of $0.56 \mathrm{l}$ given by the manufacturer is $w=(1200 \pm 60) \mathrm{Bq} \cdot \mathrm{m}^{-3} / \mathrm{s}^{-1}$.

\subsection{Characteristic limits}

The decision threshold $c_{\mathrm{A}}{ }^{*}$ for the successful detection of Rn-222 activity concentration in air using the ionisation chamber according to ISO 11929 (2010) is

$$
c_{\mathrm{A}}^{*}=k_{1-\alpha} \sqrt{w^{2}\left(\frac{r_{0}}{t_{\mathrm{g}}}+\frac{r_{0}}{t_{0}}\right)}
$$

with

$c_{\mathrm{A}}{ }^{*} \quad$ decision threshold of detection of the Rn-222 activity concentration in air $\left(\mathrm{Bq} \mathrm{m}{ }^{-3}\right)$

$k_{1-\alpha} \quad$ coverage factor of the standard normal distribution quantile $\phi\left(k_{1-\alpha}\right)=1-\alpha$ if the error of the first kind is $\alpha$, which is the probability of the false decision on detection ('false detection'). If $\alpha=5 \%$ then $k_{1-\alpha}=1.645$.

The lower limit of detection $c_{\mathrm{A}}^{\#}$ of the used ionisation chamber for the Rn-222 in air measurement is

$$
c_{\mathrm{A}}^{\#}=c_{\mathrm{A}}^{*}+k_{1-\beta} \cdot u\left(c_{\mathrm{A}}^{\#}\right)
$$

with 
$\mathrm{CA}^{\#} \quad$ lower limit of detection of the $\mathrm{Rn}-222$ activity concentration in air $\left(\mathrm{Bq} \mathrm{m}^{-3}\right)$

$k_{1-\beta} \quad$ coverage factor of the standard normal distribution quantile $\phi\left(k_{1-\beta}\right)=1-\beta$ if the error of the second kind is $\beta$, which is the probability of the false decision on no detection ('false no detection'). If $\beta=5 \%$ then $k_{1-\beta}=1.645$.

In most cases, relation formula (3) can be solved convergently by iteration with

$$
c_{\mathrm{A}, i+1}^{\#}=c_{\mathrm{A}}^{*}+k_{1-\beta} \cdot u\left(c_{\mathrm{A}, i}^{\#}\right)
$$

starting the iteration at $i=0$ with

$$
c_{\mathrm{A}, 0}^{\#}=2 \cdot c_{\mathrm{A}}^{*}
$$

In most cases, if the condition $r_{0} \cdot t_{0} \geq 50$ is fulfilled, the practicable approximation according to the Austrian standard ON S 5250-1 (2001) for the lower limit of detection gives a satisfactory result for the lower limit of detection

$$
c_{\mathrm{A}}^{\#}=c_{\mathrm{A}}^{*}+k_{1-\beta} \cdot \sqrt{w^{2}\left(\frac{r_{0}}{t_{\mathrm{g}}}+\frac{r_{0}}{t_{0}}\right)}=\left(k_{1-\alpha}+k_{1-\beta}\right) \cdot \sqrt{w^{2}\left(\frac{r_{0}}{t_{\mathrm{g}}}+\frac{r_{0}}{t_{0}}\right)}
$$

If using $t_{\mathrm{g}}=t_{0}$ and $\alpha=\beta=5 \%$, then formulas (3) and (6) simplify approximately to

$$
\begin{aligned}
& c_{\mathrm{A}}^{*} \cong 2.33 \sqrt{w^{2}\left(\frac{r_{0}}{t_{0}}\right)} \\
& c_{\mathrm{A}}^{\#} \cong 4.65 \sqrt{w^{2}\left(\frac{r_{0}}{t_{0}}\right)}
\end{aligned}
$$

In this work, $\operatorname{tg}_{\mathrm{g}}=t_{0}=3600 \mathrm{~s}$ and $\alpha=\beta=5 \%$ have been selected for practical reasons. The typical value of the used ionisation chamber background count rate has been determined in a period $t_{0}=3600 \mathrm{~s}$ with $r_{0}=0.013(0.003) \mathrm{s}^{-1}$. Considering the detection efficiency of the used ionisation chamber $w=1200(60) \mathrm{Bq} \mathrm{m}^{-3} / \mathrm{s}^{-1}$, the decision threshold and the lower limit of detection can be approximated according to (7) and (8) respectively with

$$
c_{\mathrm{A}}^{*} \cong 2.33 \sqrt{1200^{2}\left(\frac{0.013}{3600}\right)} \mathrm{Bq} \cdot \mathrm{m}^{-3}=5.3 \mathrm{~Bq} \cdot \mathrm{m}^{-3}
$$

and

$$
c_{\mathrm{A}}^{\#} \cong 4.65 \sqrt{1200^{2}\left(\frac{0.013}{3600}\right)} \mathrm{Bq} \cdot \mathrm{m}^{-3}=10.6 \mathrm{~Bq} \cdot \mathrm{m}^{-3}
$$

The emanation of the Rn-222 activity $A_{\mathrm{w}}\left(T_{\mathrm{m}}\right)$ from the water sample at the time of measurement $T_{\mathrm{m}}$ into the closed air volume of the calibration container barrel is almost 100 $\%$. Therefore, the resulting Rn-222 activity concentration $c_{\mathrm{A}}\left(T_{\mathrm{m}}\right)$ in the container at the time of measurement $T_{\mathrm{m}}$ is

$$
c_{\mathrm{A}}\left(T_{\mathrm{m}}\right)=\frac{A_{\mathrm{w}}\left(T_{0}\right)}{V_{\mathrm{c}}} \cdot K_{\Delta t}=\frac{c_{\mathrm{A}, \mathrm{w}} \cdot V_{\mathrm{W}}}{V_{\mathrm{c}}} \cdot e^{-\ln (2) \cdot \frac{\Delta t}{T_{1 / 2}}}
$$

with 
$A_{\mathrm{w}}\left(T_{0}\right)$ activity of the water sample at the time of sampling $T_{0}(\mathrm{~Bq})$

$V_{\mathrm{c}} \quad$ air volume of the calibration container $\left(\mathrm{m}^{3}\right)$

$K_{\Delta \mathrm{t}} \quad$ Correction factor for the radioactive decay of $\mathrm{Rn}-222$

$C_{\mathrm{A}, \mathrm{w}}$ activity concentration of the water sample $\left(\mathrm{Bq} \cdot \mathrm{l}^{-1}\right)$

$V_{\mathrm{w}} \quad$ volume of the water sample (l)

$\Delta t \quad$ time span between sampling and measurement $\left(T_{\mathrm{m}}-T_{0}\right)(\mathrm{d})$

$T_{1 / 2} \quad$ half-life of Rn-222: 3.8232 (8) d

Finally, the interesting Rn-222 activity concentration $c_{\mathrm{A}, \mathrm{w}}\left(T_{0}\right)$ of the water sample $\left(\mathrm{Bq} \cdot \mathrm{l}^{-1}\right)$ at the moment of sampling $T_{0}$ considering formula (1) in (9) yield into

$$
c_{\mathrm{A}, \mathrm{w}}\left(T_{0}\right)=\frac{A_{\mathrm{w}}\left(T_{0}\right)}{V_{\mathrm{w}}}=\frac{c_{\mathrm{A}}\left(T_{\mathrm{m}}\right) \cdot V_{\mathrm{c}}}{V_{\mathrm{w}} \cdot K_{\Delta t}}=\frac{w \cdot\left(r_{\mathrm{g}}-r_{0}\right) \cdot V_{\mathrm{c}}}{V_{\mathrm{w}}} \cdot e^{\ln (2) \cdot \frac{\left(T_{m}-T_{0}\right)}{T_{1 / 2}}}
$$

\section{Traceable calibration of the ionisation chamber}

The traceable calibration of the used ionisation chamber for this research has been performed at the National Institute of Ionisation Radiation Metrology INMRI at ENEA, Italy, at reference Rn-222 activity concentrations from $272 \mathrm{~Bq} \mathrm{~m}^{-3}$ to $19938 \mathrm{~Bq} \mathrm{~m}^{-3}$. In total, 515 readings, each of $60 \mathrm{~min}$ integration time have been performed. Two calibration points at constant reference radon activity concentrations have been carried out in the INMRI one cubic meter calibration chamber, another four calibration cycles have been done in the INMRI walk-in radon calibration chamber.

In Table 1, the results of the metrological traceable calibration of the used BEV radon ionisation chamber at the designated laboratory for ionizing radiation of Italy, ENEA, National Institute of Ionizing Radiation (INMRI) are shown. The BEV radon ionisation chamber is the Austrian national standard for radon activity concentration (Rn-222 and Rn220 ) in air. The BEV Rn ionisation chamber is a traceably calibrated metrological secondary standard.

\subsection{Calibration factor}

The calibration factor $K$ (Table 1$)$ is defined as

$$
K=\frac{c_{A, r e f}}{c_{A}}
$$

with

$c_{\text {A,ref }}$ traceable reference Rn-222 activity concentration in air of the ENEA standard $\left(\mathrm{Bq} \cdot \mathrm{m}^{-3}\right)$

$c_{\mathrm{A}} \quad \mathrm{Rn}-222$ activity concentration in air measured by the BEV ionisation chamber $\left(\mathrm{Bq} \cdot \mathrm{m}^{-3}\right)$ 
The results of the traceable calibration of the BEV radon ionisation chamber are compiled in Table 1. Two of the six calibration points had been carried out at constant and four points at variable radon reference activity concentrations. In Figure 3 the course of the reference standard instrument and device under calibration is shown for the variable radon activity concentration course.

Finally, the calibration work - six calibration points (Table 1) - resulted in a mean value of the calibration factor $K=1.016 \pm 0.033$ for the BEV ionisation chamber in the range of Rn222 activity concentrations in air between $270 \mathrm{~Bq} \mathrm{~m}^{-3}$ and $20000 \mathrm{~Bq} \mathrm{~m}^{-3}$ (Table 1).

The calibration gives the traceable measured Rn-222 activity concentration $c_{\mathrm{A}, \mathrm{w}}\left(T_{0}\right)$ at the sampling time $T_{0}$ of the measured water samples applying (11) in (10)

$$
c_{\mathrm{A}, \mathrm{w}}\left(T_{0}\right)=\frac{K \cdot c_{\mathrm{A}}\left(T_{\mathrm{m}}\right) \cdot V_{\mathrm{c}}}{V_{\mathrm{w}} \cdot K_{\Delta t}}=\frac{K \cdot w \cdot\left(r_{\mathrm{g}}-r_{0}\right) \cdot V_{\mathrm{c}}}{V_{\mathrm{w}}} \cdot e^{\ln (2) \cdot \frac{\left(T_{m}-T_{0}\right)}{T_{1 / 2}}}
$$

Considering the calibration factor $K$, the characteristic limits $C^{*}{ }_{\mathrm{A}, \mathrm{w}}\left(T_{0}\right)$ and $c^{\#} \mathrm{A, \textrm {w }}\left(T_{0}\right)$ at the sampling time $T_{0}$ can be estimated according to (7) and (8) to

$$
\begin{aligned}
& c_{\mathrm{A}, \mathrm{w}}^{*}\left(T_{0}\right) \cong 2.33 \cdot \frac{K \cdot w \cdot V_{\mathrm{c}}}{V_{\mathrm{w}}} \cdot e^{\ln (2) \cdot \frac{\left(T_{m}-T_{0}\right)}{T_{1 / 2}}} \sqrt{\left(\frac{r_{0}}{t_{0}}\right)} \\
& c_{\mathrm{A}, \mathrm{w}}^{\#}\left(T_{0}\right) \cong 4.65 \cdot \frac{K \cdot w \cdot V_{\mathrm{c}}}{V_{\mathrm{w}}} \cdot e^{\ln (2) \cdot \frac{\left(T_{m}-T_{0}\right)}{T_{1 / 2}}} \sqrt{\left(\frac{r_{0}}{t_{0}}\right)}
\end{aligned}
$$

\section{Results and discussion}

\subsection{Result of the method validation}

The new method has been validated by the emanation of the BEV radium 226 solution in water standard Radotto 4 (traceable to PTB), complete emanation of the radon 222 activity which was in radioactive equilibrium with the radium 226 activity - out of the water into the calibration barrel air and measurement with the traceable calibrated ionisation chamber. The complete validation measurement is shown in Figure 4. The BEV ionisation chamber had been operated in diffusion mode with 10 min counting integration periods. Because of the statistically satisfied count rate, the measurement period had been reduced to 4 x $10 \mathrm{~min}$. In this period the mean count rate resulted in $r_{\mathrm{g}}=10.58(0.33) \mathrm{s}^{-1}$ which is equivalent to a mean radon 222 in air concentration in the calibration barrel of $12.69(0.40) \mathrm{Bq} \cdot \mathrm{m}^{3}$ (Figure 4).

The complete results of the validation measurement including the uncertainty budget is compiled in Table 2.

The traceable certified value (PTB) of the BEV radium 226 activity standard Radotto 4 is 2548 (127) Bq. The radioactive equilibrium between radon 222 and radium 226 had been 
established by closing the standard bottle for about three months. This resulted in an emanated radon 222 activity of 2548 (127) Bq. This means 2548 (127) Bq. $\mathrm{l}^{-1}$ in relation to $1 \mathrm{l}$ water.

Considering the uncertainties of the radon 222 reference activity concentration value of 2548 (127) Bq. $\mathrm{l}^{-1}$ compared to the outcome of the validation measurement of 2642 (179) Bq. $\mathrm{l}^{-1}$ (Table 2), there is no statistically significant deviation between the traceable reference value and the measurement value. Therefore, the complete method has been validated successfully.

In Figure 5, the measurement of water sample under investigation W05-2, Elisabethquelle, Bad Gastein, Salzburg, Austria, is shown in detail. After flushing the calibration barrel with low radon 222 fresh air, the background count rate has been measured in a period of $6 \times 10$ min. Then the sample bottle has been inserted in the barrel and after closing the barrel, the radon 222 has been emanated as described in Figure 2. The integration period of $6 \times 10$ min for averaging the count rate has been started 20 min after the radon 222 emanation start. Immediately after the integration (averaging) period, the water sample has been removed from the calibration barrel and the barrel has been flushed again with low radon fresh air, preparing for the next sample measurement.

In Table 3 the evaluation of the measurement is compiled completely. The mean gross count of the measurement in the integration period is $0.418(0.030) \mathrm{s}^{-1}$. This gives a mean measured radon 222 activity concentration in the barrel air of 501 (36) $\mathrm{Bq} \cdot \mathrm{m}^{-3}$ (Figure 5).

\subsection{Uncertainty budget of $c_{\mathrm{A}, \mathrm{w}, \mathrm{ref}}\left(T_{0}\right)$}

The uncertainty budget according to the final model equation (13) for the measurement of the Rn-222 activity concentration of water samples gives the resulting standard uncertainty $u\left(c_{\mathrm{A}, \mathrm{w}}\left(T_{0}\right)\right)$ to

$$
u^{2}\left(c_{\mathrm{A}, \mathrm{w}, \mathrm{ref}}\left(T_{0}\right)\right)=\sum_{i}\left[\left(\frac{\partial c_{\mathrm{A}, \mathrm{w}}\left(T_{0}\right)}{\partial x_{i}}\right)^{2} \cdot u^{2}\left(x_{i}\right)\right]
$$

with

$x_{\mathrm{i}} \quad$ input variables of the model equation (10): $K, w, r_{\mathrm{g}}, r_{0}, V_{\mathrm{c}}, V_{\mathrm{w}}$, $\Delta t=\left(T_{\mathrm{m}}-T_{0}\right), T_{1 / 2}$

The value and uncertainty of the volume of the calibration container barrel had been carefully determined by traceable measurements of the all dimensions including the instruments, materials and installations e.g. ionisation chamber, fan, bottle material, hoses, air pump outside the barrel etc. (Figure 2). This careful traceable determination lead to a net air volume of the calibration container barrel $V_{\mathrm{c}}=0.2044(000.6) \mathrm{m}^{3}$ (Table 3).

In Table 3 the complete uncertainty budget of measurement of water sample W05-2 is given. The main contributions to the total measurement uncertainty come from the uncertainties of the gross count rate $r_{\mathrm{g}}$, the ionisation chamber detection efficiency $w$ and the calibration factor $K$. Less impact on the total uncertainty have the uncertainties of the water sample volume $V_{\mathrm{w}}$, 
the radon 222 half-life $T_{1 / 2}$, the time between sampling and measurement $\Delta t$, and the calibration container air volume $V_{\text {c }}$.

\subsection{Measurement results}

In Table 4 the measurement results of the drinking water samples collected in summer 2018 including the validation measurement is collocated. The results of the water sample measurements are sorted in ascending order of the time between sampling and measurement $\Delta t$. This shows clearly the increasing measurement uncertainties and characteristic limits of the measurements depending on the reduced gross count rate with time progress because of the radioactive decay of radon 222 (half-life 3.8232 (8) days).

The minimal reachable lower limit of detection $c^{\#}$ A of radon 222 in a water 11 sample for 60 min measurement period is $2 \mathrm{~Bq} \cdot \mathrm{l}^{-1}$ when the measurement is immediately done after the sampling. Depending on the radon activity concentration of the water sample and the time between sampling and measurement, the relative uncertainties of the measured water samples lay between $7 \%$ and $108 \%$.

Demonstrated by the results shown in Table 4, for a similar elapsed time between sampling and measurement, the radon concentration is the dominant contribution to the uncertainty and vice versa, for similar activity concentrations, the elapsed time makes the dominant impact to the uncertainty.

In relation to the legal requirements given in the EU Council Directive 2013/51 laying down requirements for the protection of the health of the general public with regard to radioactive substances in water intended for human consumption, the hereby introduced new traceable radiometrological measurement method is successfully applicable if considering the methodological limitations in regard to the directed indication and action levels for radon 222 in drinking water. In Annex 1 of the Directive the requirements for radon 222 in drinking water are given as follows:

(a) Member States may set a level for radon 222 which is judged inappropriate to be exceeded and below which optimisation of protection should be continued, without compromising water supply on a national or regional scale. The level set by a Member State may be higher than $100 \mathrm{~Bq} \cdot \mathrm{l}^{-1}$ but lower than $1000 \mathrm{~Bq} \cdot \mathrm{l}^{-1}$. In order to simplify national legislation, Member States may choose to adjust the parametric value to this level.

(b) Remedial action is deemed to be justified on radiological protection grounds, without further consideration, where radon 222 concentrations exceed $1000 \mathrm{~Bq} \cdot \mathrm{l}^{-1}$.

The hereby given activity concentration values for radon 222 are 'parametric values' according the definition given in Article 2 (4) of the Directive and means the value of radon 222 in water intended for human consumption above which Member States shall assess whether the presence of radioactive substances in water intended for human consumption poses a risk to human health which requires action and, where necessary, shall take remedial action to improve the quality of water to a level which complies with the requirements for the protection of human health from a radiation protection point of view. 
Comparing the deemed remedial action level of $1000 \mathrm{~Bq} \cdot \mathrm{l}^{-1}$ for radon 222, the herby introduced traceable measurement method gives acceptable results even if the measurement is done 29 days after the sampling. But in general, it is recommendable to do the measurement as quick as possible after the sampling to reduce the total measurements uncertainty and the decision threshold. This is an important measurement requirement to minimise the risk of the undetected exceeding of the radon 222 action limit for drinking water of $1000 \mathrm{~Bq} \cdot \mathrm{l}^{-1}$ because of too high total measurement uncertainties.

\section{Conclusions}

An innovative quick, safe and simple applicable low-level radionuclide metrology technique for the traceable measurement of radon 222 activity concentration in drinking water using a $0.56 \mathrm{l}$ ionisation chamber operating in spectrometric pulse mode has been developed, tested, verified and applied to 16 water samples successfully. The impact of essential influencing factors and parameters on the measurement results has been investigated, discussed in detail and considered in the uncertainty budget and the calculation of the characteristic limits of the measurement method according to ISO 11929:2010 and ON S 5250-1:2004. Finally, the new method has been assessed regarding the applicability on the requirements laid down in the EU Council Directive 2013/51 concerning the EU Member States legal limitation of radon 222 activity concentration in drinking water.

The measured radon 222 activity concentrations of the measured water samples lay between 133 (48) Bq.l ${ }^{-1}$ and 2642 (179) Bq. $\mathrm{l}^{-1}$.The main contributions to the total measurement uncertainty come in by the uncertainties of the gross count rate, the ionisation chamber detection efficiency and the calibration factor. Less impact on the total measurement uncertainty is caused by the uncertainties of the water sample volume, the radon 222 half-life, the time between sampling and measurement, and the calibration container barrel net air volume.

The results of this investigation and their evaluation show clearly the increasing measurement uncertainty and increasing characteristic limits of the measurements depending on the reducing count rate with time progress because of the radioactive decay of radon 222 (halflife 3.8232 (8) days) in the stored water samples before measurement.

The uncertainties and characteristic limits of the method are increased due to the reduction of the radon 222 activity concentration from the water bottle (about $1 \mathrm{l}$ ) to the air volume of the calibration barrel $\left(0.2042 \mathrm{~m}^{3}\right)$.

The minimal reachable lower limit of detection $c^{\#} \mathrm{~A}, \mathrm{w}\left(T_{0}\right)$ of radon 222 in a $1 \mathrm{l}$ water sample for a 60 min measurement period is calculated according to ISO 11929:2010 in combination with ON S 5250-1:2004 with $c^{\#} \mathrm{~A}=2 \mathrm{~Bq} \cdot \mathrm{l}^{-1}$ when the measurement is immediately done after the sampling. If the measurement is done not later than about 26 days after the sample collection, the decision threshold of detection of radon 222 in the analysed $1 \mathrm{l}$ water sample $c^{*} \mathrm{~A}, \mathrm{w}\left(T_{0}\right)$ is below $100 \mathrm{~Bq} \cdot \mathrm{l}^{-1}$ (Table 4). 
The relative uncertainties of the measured water samples lay between $7 \%$ and $108 \%$ depending on the value of the radon activity concentration of the water sample and the time between sampling and measurement (Table 4, Figure 6).

It is recommended to do the measurements as quick as possible after collecting the water samples to reduce the total measurements uncertainty and the characteristic limits (decision threshold and lower limit of detection) because of avoiding too much radioactive decay of radon 222. This is an important measurement requirement to minimise undetected exceeding of the radon 222 action limit for drinking water because of too high total measurement uncertainties.

Comparing to the remedial action level of $1000 \mathrm{~Bq} \cdot \mathrm{l}^{-1}$ for radon 222 deemed in the EU Council Directive 2013/51, the introduced measurement method gives successfully acceptable results particularly regarding the radiation protection requirement on the public.

\section{Acknowledgement}

This work performed in the joint research project MetroRADON has received funding from the EMPIR programme co-financed by the Participating States and from the European Union's Horizon 2020 research and innovation programme.

\section{References}

DDEP, 2019. Data Decay Evaluation Project. Accessed 2019-04-17, 14:30. http://www.nucleide.org/DDEP_WG/Nuclides/Rn-222_tables.pdf

Ditto, M., et al. 2007. Strahlenexposition durch Trinkwasser in Oberösterreich - 2004 bis 2006 - Teilprojekt Strahlenexposition von Beschäftigten in oberösterreichischen Wasserwerken - Zusammenfassender Endbericht. Linz: Land Oberösterreich, Abteilung Umwelt- und Anlagentechnik, 2007.

European Union, 2016. Consolidated Version of the Treaty Establishing the European Atomic Energy Community. Article 35-36.

European Union, 2013. Council Directive 2013/51/Euratom laying down requirements for the protection of the health of the general public with regard to radioactive substances in water intended for human consumption.

Fonollosa, E., Peñalver, A., Borrull, F., Aguilar, C., 2016. Radon in spring waters in the south of Catalonia. J. Environ. Radioact. 151, 275-281.

Friedmann, H. 1977. Modell für die Entemanierung radioaktiver Lösungen (Model for the deemanation of radioactive solutions). Anzeiger der mathematisch naturwissenschaftlichen Klasse der österreichischen Akademie der Wissenschaften. 1977, Vol. 114, 7.

Gundersen, L., Wanty, R. (Editors). 1993. Field Studies of Radon in Rocks, Soils, and Water. C. K. Smoley, Boca Raton

Harb, S., Abbady A., El-Kamel A., Saleh I., El-Mageed A. 2012. Natural radioactivity and their radiologica leffects for different types of rocks from Egypt. Radiat. Phys. Chem. 81 (2012) 221-225

Health Canada, 2009. Guidelines for Canadian Drinking Water Quality: Guideline Technical Document, Radiological Parameters. Federal-Provincial-Territorial Committee on 
Drinking Water of the Federal-Provincial-Territorial Committee on Health and the Environment, Ottawa. Accessed 2019-04-17, 10:00. http://www.hc-sc.gc.ca/ewhsemt/alt_formats/hecs-sesc/pdf/pubs/water-eau/radiological_pararadiologiques/radiological_para-radiologiques-eng.pdf

ISO 11929:2010. Determination of the characteristic limits (decision threshold, detection limit and limits of the confidence interval) for measurements of ionizing radiation Fundamentals and application. International Standards Organisation, Geneva, Switzerland.

Jobbágy, V., Altzitzoglou, T., Malo, P., Tanner, V., Hult. M. 2017. A brief overview on radon measurements in drinking water. J. Environ. Radioact. (173), 18-24

Jobbágy, V., Stroh, H., Marissens, G., Hult, M., 2019: Comprehensive study on the technical aspects of sampling, transporting and measuring radon-in-water. Journal of Environmental Radioactivity 197 (2019) 30-38

Ibrahiem, N. 2003. Radioactive disequilibrium in the different rocktypes in Wadi Wizr, the Eastern Desert of Egypt. Appl Radiat Isot. 58 (2003) 385-392

Ringer, W., Kaineder, H., 2007. Strahlenexposition durch Trinkwasser in Oberösterreich 2004 bis 2006 - Teilprojekt Strahlenexposition von Beschäftigten in oberösterreichischen Wasserwerken - Zusammenfassender Endbericht. Linz: Amt der Oberösterreichischen Landesregierung, Abt. Umwelt- und Anlagentechnik.

Rühle, H. 1997. Radon in unserer Umwelt und die damit verbundene Strahlenexposition in der Bevölkerung (Radon in our environment and the related exposition of the public). [ed.] Karl Aurand and Horst Rühle. Radon und Trinkwasser. Berlin: Schriftenreihe des Vereins für Wasser,- Boden,- und Lufthygiene, 1997, Vol. 101, pp. 39-55.

United Nations Scientific Committee on the Effects of Atomic Radiation (UNSCEAR). 2010. Sources and effects of ionizing radiation. Volume I: Sources - UNSCEAR 2008 Report to the General Assembly with Scientific Annexes. Technical report, United Nations Publication, New York

National Research Council (NRC). 1999. Risk Assessment of Radon in Drinking Water. National Academy Press, Washington, D.C.

ON S 5250-1:2001. Uncertainties of measurements and limiting values in radiation protection - Part 1: Basics. Austrian Standards International, Wien, Austria.

United Nations Scientific Committee on the Effects of Atomic Radiation (UNSCEAR), 2000. Sources and effects of ionizing radiation. Volume I: Sources - UNSCEAR 2000 Report to the General Assembly with Scientific Annexes. Technical report, United Nations Publication

Wiedner, H., Lotter, K., Karner, P., Friedmann, H., Maringer, F.J. 2018. Radon in drinking water: comparison and evaluation of two ionisation chamber activity measurement methods. Applied Radiation and Isotopes, 134, pp. 477-481

World Health Organisation (WHO). 2011. WHO Guidelines for Drinking Water Quality. Fourth Edition. WHO Press, Geneva 


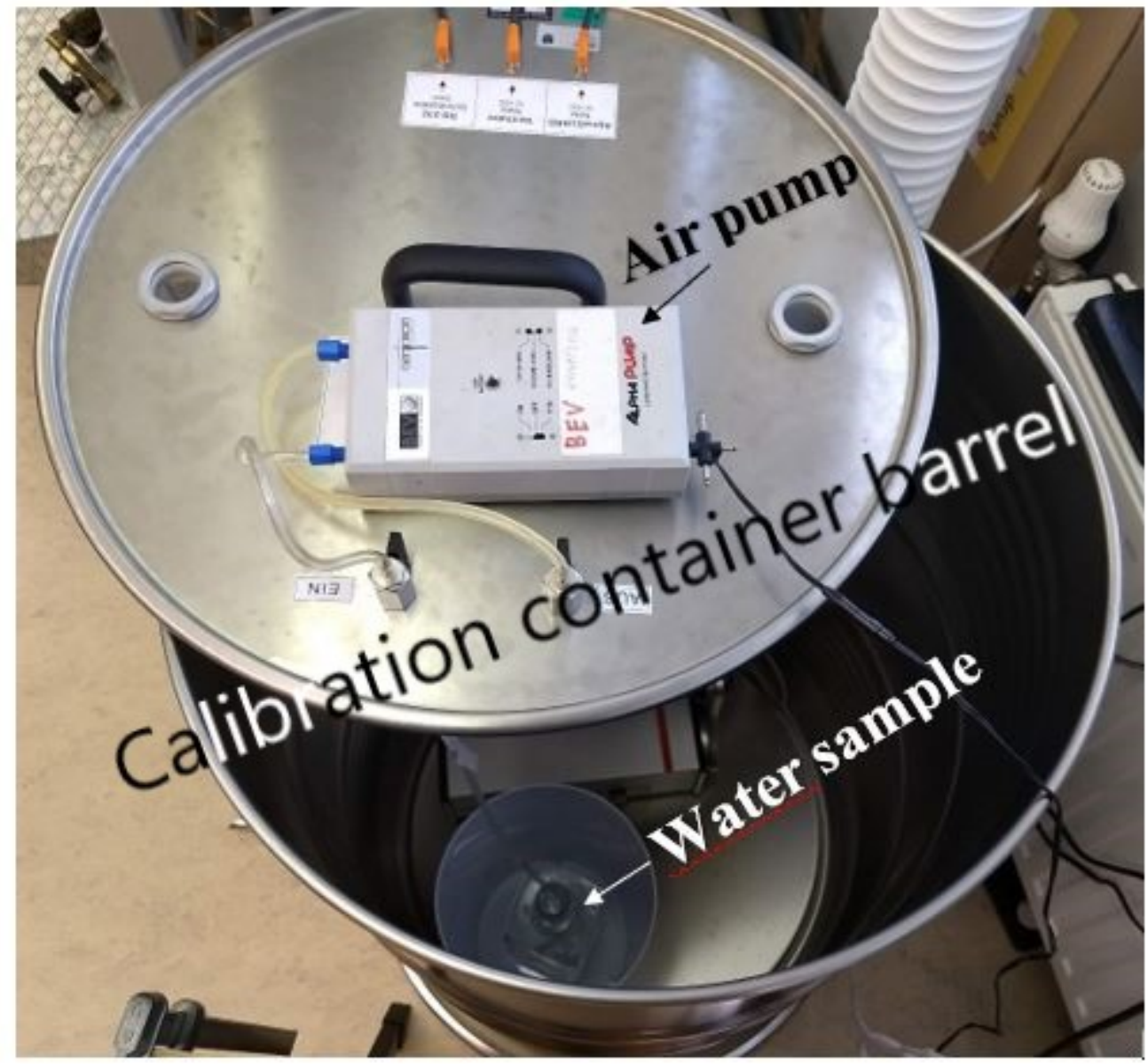

Figure 1. Radon calibration container with a drinking water sample together with the Austrian national standard ionisation chamber for radon 222 activity concentration in air inside and the air circulation pump outside the calibration container barrel 


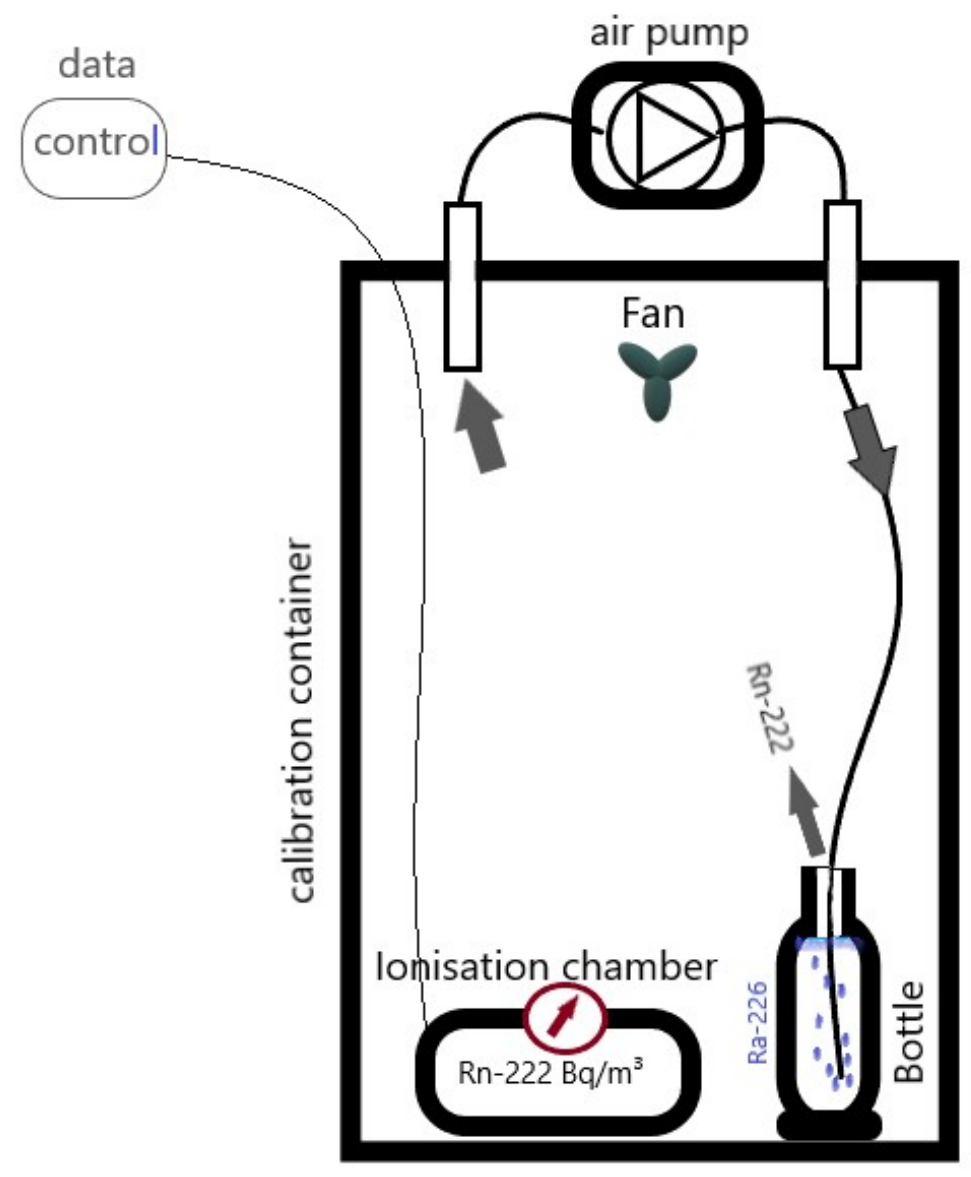

Figure 2. Schema of radon 222 emanation instrumentation and traceable measurement of drinking water samples inside the gastight radon calibration container barrel 


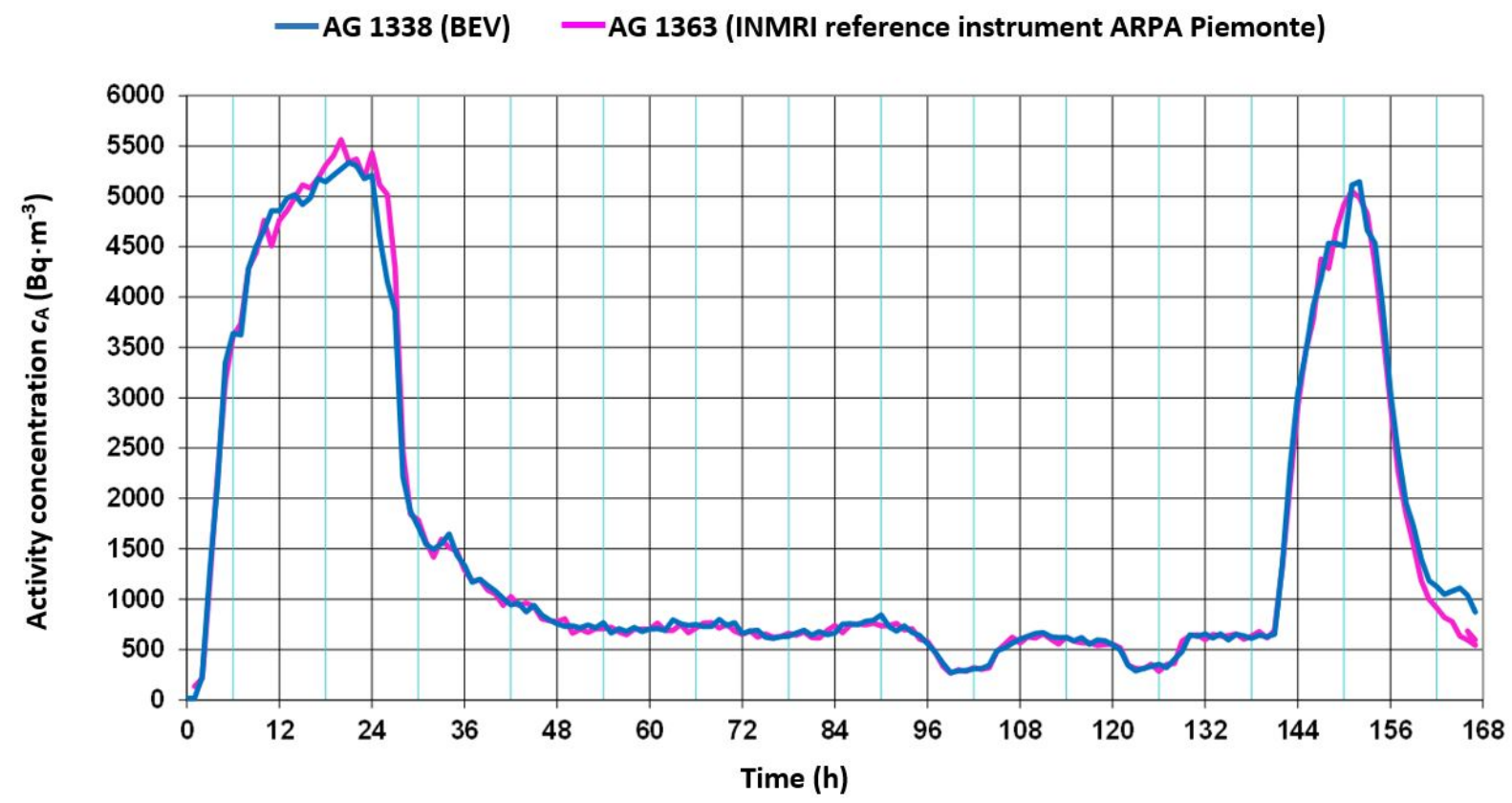

Figure 3. Calibration of the BEV ionisation chamber at ENEA's INMRI reference standard, 28/07/2016 - 03/08/2019 (calibration periods No. 708.1, 708.2 and 708.3 - Table 1) 


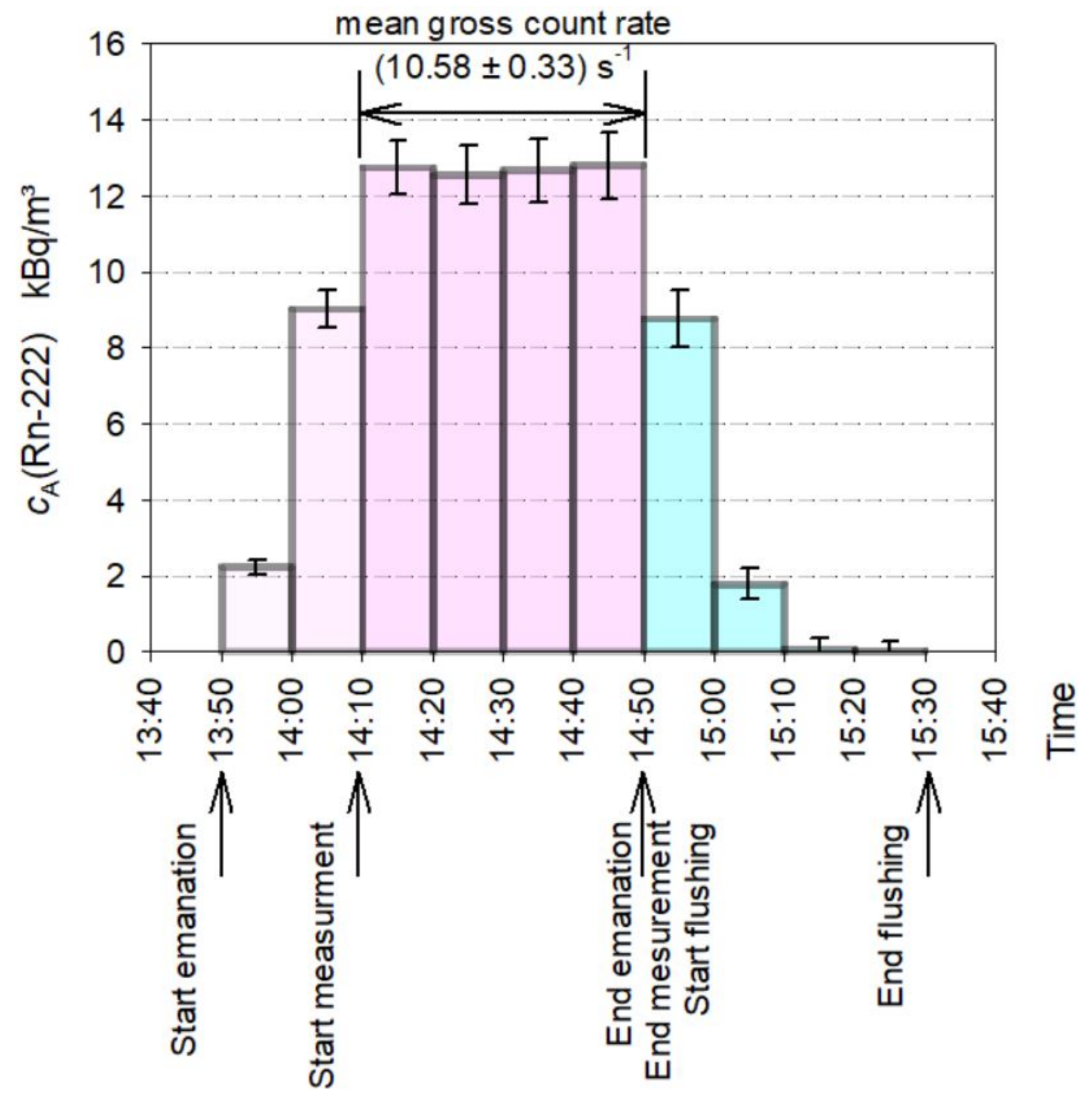

Figure 4. Rn-222 activity concentration measured by the BEV ionisation chamber result of the method validation measurement conducted on 07/02/2019 via Rn-222 emanation of a Ra-226 in water BEV standard Radotto 4, traceable to PTB 


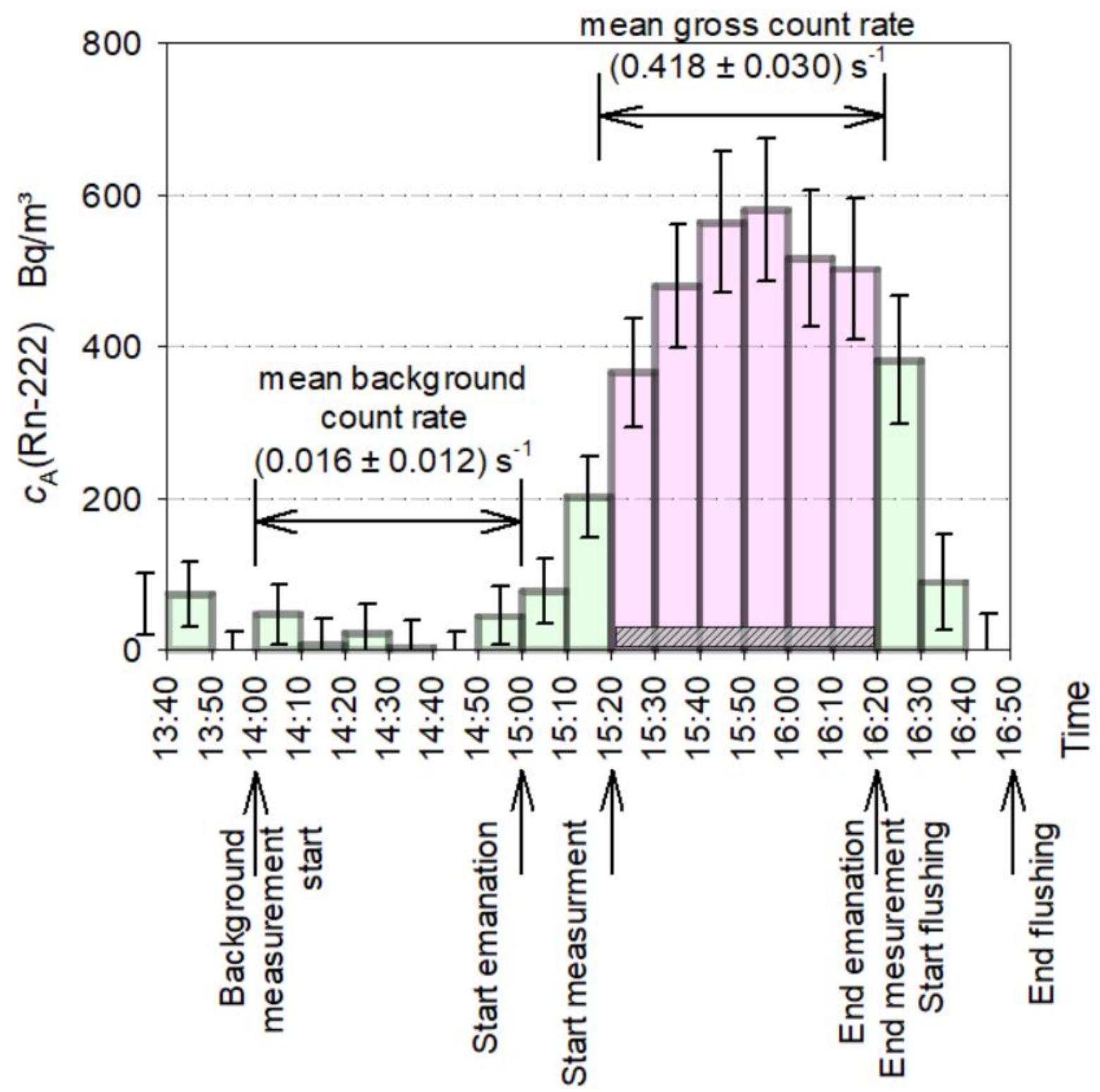

Figure 5. Rn-222 activity concentration measured by the BEV ionisation chamber result of the measurement of water sample W05-2, Elisabethquelle (8-12) 


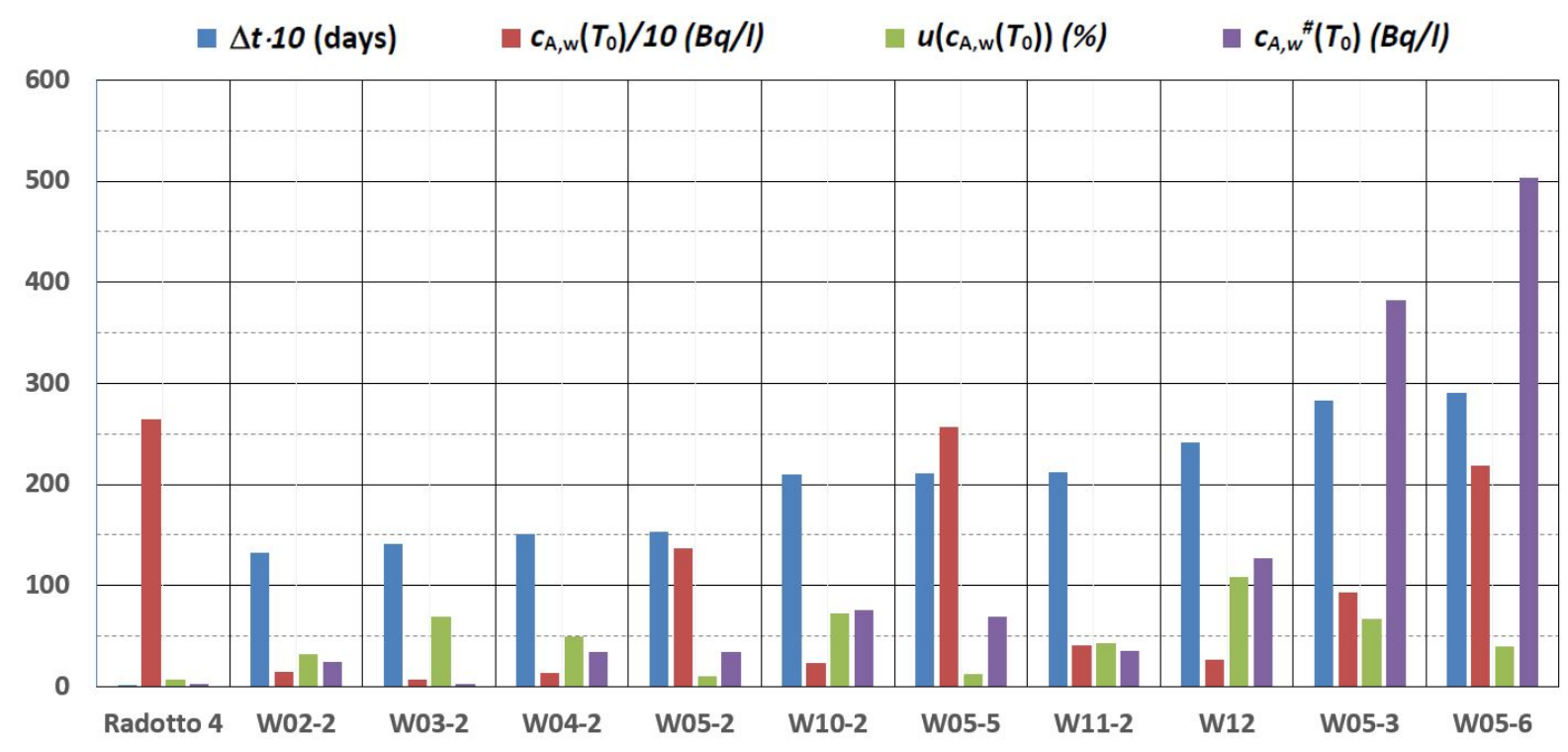

Figure 6. Impact of the time span between sampling and measurement $\Delta t$ and the Rn-222 activity concentration of the water sample $c_{A, w}\left(T_{0}\right)$ on the measurement uncertainty $u\left(c_{\mathrm{A}, \mathrm{w}}\left(T_{0}\right)\right)$ and the lower limit of detection $c_{\mathrm{A}, \mathrm{w}}{ }^{\#}\left(T_{0}\right)$ 
Table 1. Traceable calibration of the BEV radon ionisation chamber at the National Institute of Ionizing Radiation INMRI, ENEA, Italy

\begin{tabular}{|c|c|c|c|c|c|c|}
\hline Calibr. No. & 710 & 721 & 708.1 & 708.2 & 708.3 & 709 \\
\hline $\begin{array}{r}\text { Reference radon } \\
\text { monitor }\end{array}$ & $\begin{array}{l}\text { Alphaguard } \\
\text { S/N EF } 1498 \\
\text { (INMRI) }\end{array}$ & $\begin{array}{l}\text { Alphaguard } \\
\text { S/N EF } 1613 \\
\text { (INMRI) }\end{array}$ & \multicolumn{4}{|c|}{$\begin{array}{c}\text { Alphaguard S/N EF } 1363 \\
\text { (INMRI reference instrument ARPA Piemonte) }\end{array}$} \\
\hline $\begin{array}{r}\text { Monitor under } \\
\text { calibration }\end{array}$ & \multicolumn{6}{|c|}{ Alphaguard S/N EF 1338 (BEV) } \\
\hline $\begin{array}{r}\text { Date of } \\
\text { measurement }\end{array}$ & $\begin{array}{l}\text { 02/09/2016 to } \\
05 / 09 / 2016\end{array}$ & $\begin{array}{l}14 / 10 / 2016 \text { to } \\
18 / 10 / 2016\end{array}$ & $\begin{array}{l}28 / 07 / 2016 \\
\text { to } \\
29 / 07 / 2016\end{array}$ & $\begin{array}{l}30 / 07 / 2016 \\
\text { to } \\
03 / 08 / 2016\end{array}$ & $\begin{array}{l}03 / 08 / 2016 \\
\text { to } \\
04 / 08 / 2016\end{array}$ & $\begin{array}{l}12 / 08 / 2016 \\
\text { to } \\
20 / 08 / 2016\end{array}$ \\
\hline $\begin{array}{r}\text { Settings of monitor } \\
\text { under calibration }\end{array}$ & \multicolumn{6}{|c|}{ Integration time $60 \mathrm{~min}$, diffusion mode. } \\
\hline $\begin{array}{r}\text { Measurement } \\
\text { condition }\end{array}$ & \multicolumn{2}{|c|}{$\begin{array}{l}\text { Measurement at constant radon } \\
\text { concentration in one cubic meter } \\
\text { radon chamber }\end{array}$} & \multicolumn{4}{|c|}{$\begin{array}{l}\text { Measurement at variable radon concentration in walk-in } \\
\text { radon chamber }\end{array}$} \\
\hline $\begin{array}{r}\text { Air temperature } \\
\text { during measurement } \\
\left({ }^{\circ} \mathrm{C}\right) \\
\end{array}$ & $21.9 \pm 0.6$ & $20.8 \pm 0.6$ & $25.6 \pm 0.1$ & $26.8 \pm 0.3$ & $27.0 \pm 0.3$ & $27.0 \pm 1.0$ \\
\hline $\begin{array}{l}\text { Air pressure during } \\
\text { measurement }(\mathrm{hPa})\end{array}$ & $1002 \pm 2$ & 993 to 1009 & $1000 \pm 1$ & $999 \pm 1$ & $1000 \pm 1$ & 996 to 1007 \\
\hline $\begin{array}{r}\text { Relative air } \\
\text { humidity during } \\
\text { measurement (\%) }\end{array}$ & $43 \pm 2$ & 44 to $66(*)$ & $73 \pm 1$ & $73 \pm 2$ & $70 \pm 1$ & $62 \pm 4$ \\
\hline $\begin{array}{r}\text { Reference radon } \\
\text { activity } \\
\text { concentration } \\
C_{\mathrm{A}, \text { ref }}\left(\mathrm{Bq} \mathrm{m}^{-3}\right) \\
\end{array}$ & $9152 \pm 138$ & $17512 \pm 259$ & $\begin{array}{l}\text { Average } \\
4850 \\
\min 3624 \\
\max 5336 \\
\end{array}$ & $\begin{array}{l}\text { Average } 632 \\
\min 272 \\
\max 960\end{array}$ & $\begin{array}{l}\text { Average } \\
3462 \\
\min 1344 \\
\max 5144 \\
\end{array}$ & $\begin{array}{c}\text { Average } \\
14437 \\
\min 6530 \\
\max 19938 \\
\end{array}$ \\
\hline $\begin{array}{r}\text { Number of readings } \\
\text { of the monitor } \\
\text { under calibration }\end{array}$ & 72 & 83 & 21 & 97 & 97 & 145 \\
\hline $\begin{array}{r}\text { Blank indication of } \\
\text { monitor under } \\
\text { calibration }\end{array}$ & \multicolumn{6}{|c|}{$\begin{array}{l}\text { evaluated based on } 25 \text { hours measurement at low radon concentration }\left(10 \pm 4 \mathrm{~Bq} \mathrm{~m}^{-3}\right) \\
\text { in one cubic meter radon chamber }\end{array}$} \\
\hline $\begin{array}{r}\text { Average readings of } \\
\text { monitor under } \\
\text { calibration } c_{\mathrm{A}}(\mathrm{Bq} \\
\left.\mathrm{m}^{-3}\right)\end{array}$ & $8932 \pm 127$ & $17120 \pm 147$ & $\begin{array}{c}\text { Average } \\
4896 \\
\min 3616 \\
\max 5568 \\
\end{array}$ & $\begin{array}{c}\text { Average } 630 \\
\min 270 \\
\max 1032\end{array}$ & $\begin{array}{c}\text { Average } \\
3400 \\
\min 1192 \\
\max 5056 \\
\end{array}$ & $\begin{array}{c}\text { Average } \\
14493 \\
\min 6496 \\
\max 20352 \\
\end{array}$ \\
\hline $\begin{array}{r}\text { Calibration } \\
\text { factor } K \\
\end{array}$ & 1025 & 1025 & 0.992 & 1011 & 1018 & 1000 \\
\hline $\begin{array}{l}\text { Uncertainty of the } \\
\text { calibration factor }\end{array}$ & \multicolumn{6}{|c|}{$3 \%$} \\
\hline $\begin{array}{r}\text { Ratio of monitor } \\
\text { readings; AG1363 / } \\
\text { AG1338 }(* *) \\
\end{array}$ & \multicolumn{2}{|c|}{ n.a. } & $\begin{array}{c}0.993 \pm \\
0.030\end{array}$ & $\begin{array}{c}1.014 \pm \\
0.070\end{array}$ & $\begin{array}{c}1.036 \pm \\
0.061\end{array}$ & $\begin{array}{c}0.999 \pm \\
0.027\end{array}$ \\
\hline
\end{tabular}

all uncertainties at $k=1$

(*) Air humidity decreases during measurement because RAD7 radon monitor with desiccant cartridge was connected to the radon chamber

(**) The ratio is $R=A_{\mathrm{r}} /(L-B)$

where $A_{\mathrm{r}}$ is the reference radon Activity, $L$ is the reading of the monitor under calibration and $B$ is his blank indication 
Table 2. Uncertainty budget and characteristic limits of BEV reference sample Radotto 4, Ra-226 water standard (traceable to PTB), emanation 07/02/2019 13:50, measurement 07/02/2019 14:30, reference Rn-222 activity conc. $c_{A, w, r e f}\left(T_{0}\right)=(2548 \pm 127) B q \cdot l^{-1}$

\begin{tabular}{|c|c|c|c|c|c|c|c|c|}
\hline & Quantity & Value & unit & $u\left(x_{i}\right)$ & $u_{r e l}\left(x_{i}\right)$ & $\partial x_{i} / \partial y$ & $q_{i}=\left(\partial x_{i} / \partial y\right)^{2} \cdot u^{2}\left(x_{i}\right)$ & $q_{\mathrm{i}} / \Sigma_{\mathrm{i}} \boldsymbol{q}_{\mathrm{i}}$ \\
\hline$x_{1}$ & K & 1.016 & & 0.033 & $3.3 \%$ & 2601 & 7527.11 & $24 \%$ \\
\hline$x_{2}$ & $w$ & 1200 & $\begin{array}{l}\mathrm{Bq} \cdot \mathrm{m}^{-3} / \mathrm{s}^{-} \\
\end{array}$ & 60 & $5.0 \%$ & 2.202 & 17454.34 & $55 \%$ \\
\hline$x_{3}$ & $r_{\mathrm{g}}$ & 10.573 & $s^{-1}$ & 0.332 & $3.1 \%$ & 250 & 6916.1 & $22 \%$ \\
\hline$x_{4}$ & $r_{0}$ & 0.013 & $s^{-1}$ & 0.003 & $25.0 \%$ & -250 & 0.70 & $0 \%$ \\
\hline$x_{5}$ & $V_{\mathrm{c}}$ & 0.2042 & $\mathrm{~m}^{3}$ & 0.0006 & $0.3 \%$ & 12940 & 60.2774 & $0.188 \%$ \\
\hline$x_{6}$ & $V_{\mathrm{w}}$ & 1.0000 & 1 & 0.0003 & $0.03 \%$ & -2642 & 0.628356 & $0.002 \%$ \\
\hline$x_{7}$ & $\Delta t=\left(T_{\mathrm{m}}-T_{0}\right)$ & 0.03 & days & 0.0125 & $45.00 \%$ & 479.05 & 35.857537 & $0.112 \%$ \\
\hline$x_{8}$ & $T_{1 / 2}$ & 3.8232 & days & 0.0008 & $0.02 \%$ & 3.48 & 0.000008 & $0.000 \%$ \\
\hline \multirow{5}{*}{$y$} & & & & & & $\Sigma_{i}\left(q_{i}\right)$ & 31995 & $100 \%$ \\
\hline & & & & & & $\sqrt{\Sigma_{i}}\left(q_{i}\right)$ & 179 & \\
\hline & Quantity & Value & unit & $u\left(c_{\mathrm{A}, w}\left(T_{0}\right)\right)$ & $u_{\mathrm{rel}}\left(c_{\mathrm{A}, \mathrm{w}}\left(T_{0}\right)\right)$ & & $c^{*}{ }_{\mathrm{A}, \mathrm{w}}\left(T_{0}\right)$ & $c^{\#}{ }_{\mathrm{A}, \mathrm{w}}\left(T_{0}\right)$ \\
\hline & $c_{\mathrm{A}, \mathrm{w}}\left(T_{0}\right)$ & 2642 & $\mathrm{~Bq} \cdot \mathrm{I}^{-1}$ & 179 & $6.8 \%$ & & 1 & 2 \\
\hline & $c_{A, w}\left(T_{0}\right)$ & 2.64 & $\mathrm{kBq} \cdot \mathrm{I}^{-1}$ & 0.18 & $6.8 \%$ & & 0.001 & 0.002 \\
\hline
\end{tabular}


Table 3. Uncertainty budget and characteristic limits of water sample W05-2 Elisabethquelle (8-12), Bad Gastein, Austria, sample collection: 22/08/2018 09:44, measurement: 06/09/2018 15:50

\begin{tabular}{|c|c|c|c|c|c|c|c|c|}
\hline & Quantity & Value & unit & $u\left(x_{i}\right)$ & $u_{\text {rel }}\left(x_{i}\right)$ & $\partial x_{i} / \partial y$ & $q_{i}=\left(\partial x_{i} / \partial y\right)^{2} \cdot u^{2}\left(x_{i}\right)$ & $q_{\mathrm{i}} / \Sigma_{\mathrm{i}} \boldsymbol{q}_{\mathrm{i}}$ \\
\hline$x_{1}$ & $K$ & 1.016 & & 0.033 & $3.3 \%$ & 1343 & 2007.52 & $11 \%$ \\
\hline$x_{2}$ & $w$ & 1200 & $\begin{array}{l}\mathrm{Bq} \cdot \mathrm{m}^{-3} / \mathrm{s}^{-} \\
\end{array}$ & 60 & $5.0 \%$ & 1.137 & 4655.17 & $25 \%$ \\
\hline$x_{3}$ & $r_{\mathrm{g}}$ & 0.418 & $s^{-1}$ & 0.030 & $7.2 \%$ & 3399 & 10344.9 & $55 \%$ \\
\hline$x_{4}$ & $r_{0}$ & 0.016 & $s^{-1}$ & 0.012 & $75.7 \%$ & -3399 & 1756.84 & $9 \%$ \\
\hline$x_{5}$ & $V_{\mathrm{c}}$ & 0.2042 & $\mathrm{~m}^{3}$ & 0.0006 & $0.3 \%$ & 6683 & 16.0763 & $0.086 \%$ \\
\hline$x_{6}$ & $V_{\mathrm{w}}$ & 1.1638 & 1 & 0.0003 & $0.03 \%$ & -1173 & 0.123732 & $0.001 \%$ \\
\hline$x_{7}$ & $\Delta t=\left(T_{\mathrm{m}}-T_{0}\right)$ & 15.25 & days & 0.0125 & $0.08 \%$ & 247.40 & 9.563411 & $0.051 \%$ \\
\hline \multirow[t]{4}{*}{$x_{8}$} & $T_{1 / 2}$ & 3.8232 & days & 0.0008 & $0.02 \%$ & 987.09 & 0.623585 & $0.003 \%$ \\
\hline & & & & & & $\Sigma_{i}\left(q_{i}\right)$ & 18791 & $100 \%$ \\
\hline & & & & & & $\sqrt{\Sigma_{i}\left(q_{i}\right)}$ & 137 & \\
\hline & Quantity & Value & unit & $u\left(c_{\mathrm{A}, \mathrm{w}}\left(T_{0}\right)\right)$ & $u_{\text {rel }}\left(c_{\mathrm{A}, \mathrm{w}}\left(T_{0}\right)\right)$ & & $c^{*}{ }_{\mathrm{A}, \mathrm{w}}\left(T_{0}\right)$ & $c^{\#}{ }_{\mathrm{A}, \mathrm{w}}\left(T_{0}\right)$ \\
\hline \multirow[t]{2}{*}{$y$} & $c_{\mathrm{A}, \mathrm{w}}\left(T_{0}\right)$ & 1365 & $\mathrm{~Bq} \cdot \mathrm{I}^{-1}$ & 137 & $10.0 \%$ & & 17 & 34 \\
\hline & $c_{A, w}\left(T_{0}\right)$ & 1.36 & $\mathrm{kBq} \cdot \mathrm{I}^{-1}$ & 0.14 & $10.0 \%$ & & 0.017 & 0.034 \\
\hline
\end{tabular}


Table 4. Final measurement results of the reference sample Radotto 4 and the water samples analysed

\begin{tabular}{|c|c|c|c|c|c|c|c|c|c|c|c|}
\hline \multirow[t]{2}{*}{ Sample } & \multirow[t]{2}{*}{ Name } & \multirow[t]{2}{*}{ Location } & \multirow[t]{2}{*}{ Sampling $T_{0}$} & \multirow[t]{2}{*}{ Measurement $T_{\mathrm{m}}$} & \multirow{2}{*}{$\begin{array}{c}\Delta t \\
\text { days }\end{array}$} & \multirow{2}{*}{$\begin{array}{c}\Delta t \\
T_{1 / 2}\end{array}$} & & $C_{A, w}\left(T_{0}\right)$ & $u\left(c_{A, w}\left(T_{0}\right)\right)$ & $C_{A, w}{ }^{*}\left(T_{0}\right)$ & $c_{A, w}^{\#}\left(T_{0}\right)$ \\
\hline & & & & & & & & $\left.\mathrm{Bq} \cdot\right|^{-1}$ & $\%$ & & $\left.y \cdot\right|^{-1}$ \\
\hline
\end{tabular}

\begin{tabular}{|c|c|c|c|c|c|c|c|c|c|c|c|}
\hline Radotto 4 & Ra-226-Standard (PTB) & BEV & 07.02.2019 13:50 & 07.02.2019 14:30 & 0.03 & 0.01 & 2642 & 179 & $7 \%$ & 1 & 2 \\
\hline W02-2 & Appartment Anne & Böckstein & 22.08.2018 08:25 & 04.09.2018 14:30 & 13.25 & 3.5 & 144 & 45 & $32 \%$ & 12 & 24 \\
\hline W01-2 & Moises Alm & Sport Gastein & 21.08.2018 18:53 & 04.09.2018 12:50 & 13.75 & 3.6 & \multicolumn{2}{|c|}{$<C^{*}{ }_{A, w}\left(T_{0}\right)$} & & 12 & 24 \\
\hline W03-2 & Evianquelle & Böckstein & 22.08.2018 09:07 & 05.09.2018 11:30 & 14.10 & 3.7 & 133 & 48 & $36 \%$ & 1 & 2 \\
\hline W04-2 & Scholzquelle & Böckstein & 22.08.2018 09:22 & 06.09.2018 11:30 & 15.09 & 3.9 & 134 & 66 & $49 \%$ & 17 & 34 \\
\hline W05-2 & Elisabethquelle (8-12) & Bad Gastein & 22.08.2018 09:44 & 06.09.2018 15:50 & 15.25 & 4.0 & 1365 & 137 & $10 \%$ & 17 & 34 \\
\hline
\end{tabular}

\begin{tabular}{|c|c|c|c|c|c|c|c|c|c|c|c|}
\hline W09-2 & Hauptmolze $2 \mathrm{Q} 2$ & Köfels & 23.08.2018 10:25 & 12.09.2018 16:30 & 20.25 & 5.3 & \multicolumn{2}{|c|}{$<C^{*}{ }_{A, w}\left(T_{0}\right)$} & & 37 & 74 \\
\hline W06-2 & Falknerhof & Niederthai, Umhausen & 22.08.2018 18:48 & 10.09.2018 11:00 & 18.67 & 4.9 & \multicolumn{2}{|c|}{$<C^{*}{ }_{A, w}\left(T_{0}\right)$} & & 24 & 49 \\
\hline W10-2 & Molze 3 Q3 & Köfels & 23.08.2018 10:30 & 13.09.2018 10:30 & 21.00 & 5.5 & 230 & 166 & $72 \%$ & 38 & 75 \\
\hline
\end{tabular}

\begin{tabular}{|c|c|c|c|c|c|c|c|c|c|c|c|}
\hline W05-5 & Elisabethquelle (1-7) & Bad Gastein & 22.08.2018 09:44 & 12.09.2018 11:50 & 21.09 & 5.5 & 2568 & 321 & $12 \%$ & 35 & 69 \\
\hline W11-2 & Viveva & Umhausen & 23.08.2018 11:10 & 13.09.2018 16:20 & 21.22 & 5.5 & 403 & 174 & $43 \%$ & 18 & 36 \\
\hline W12 & La piazza & Oberkrimml & 24.08.2018 08:30 & $17.09 .201812: 10$ & 24.15 & 6.3 & 262 & 283 & $108 \%$ & 63 & 127 \\
\hline
\end{tabular}

\begin{tabular}{|l|l|l|l|l|l|r|r|r|r|r|}
\hline W07-2 & Pension Senner & Umhausen & $23.08 .201808: 11$ & $17.09 .201816: 10$ & 25.33 & $\mathbf{6 . 6}$ & $<\boldsymbol{C}^{*}{ }_{A, w}\left(T_{0}\right)$ & $\mathbf{8 8}$ & $\mathbf{1 7 7}$ \\
\hline W08-2 & Hauptmolze 1 Q1 & Köfels & $23.08 .201810: 20$ & $19.09 .201811: 30$ & 27.05 & $\mathbf{7 . 1}$ & $<\boldsymbol{C}^{*}{ }_{A, w}\left(T_{0}\right)$ & \\
\hline W11-3 & Viveva & Umhausen & $23.08 .201811: 10$ & $20.09 .201814: 10$ & 28.13 & $\mathbf{7 . 4}$ & $<\boldsymbol{C}^{*}{ }_{A, w}\left(T_{0}\right)$ & $\mathbf{1 7 3}$ & $\mathbf{3 4 5}$ \\
\hline
\end{tabular}

\begin{tabular}{|c|c|c|c|c|c|c|c|c|c|c|c|}
\hline W05-3 & Elisabethquelle (8-12) & Bad Gastein & 22.08.2018 09:44 & 19.09.2018 15:50 & 28.25 & 7.4 & 1578 & 619 & $39 \%$ & 192 & 382 \\
\hline W05-6 & Elisabethquelle (1-7) & Bad Gastein & 22.08.2018 09:44 & 20.09.2018 10:10 & 29.02 & 7.6 & 2186 & 857 & $39 \%$ & 252 & 503 \\
\hline
\end{tabular}


